Psychother. Psychosom. 1981;35:213-216

\title{
Contents, Vol. 35, No. 4, 1981
}

\section{Contents}

Editorial In Cauda Venenum

Birgelen, J.H., van 217

STDP, for Better and Worse

Hartzuiker, J.A 218

Short-Term Psychotherapy, a Major Development for Patients and

Psychotherapy

Van Londen, J 221

Short-Term Dynamic Psychotherapy: Its History, Its Impact and Its

Future

Sifneos, P.E 224

Training in Short-Term Psychotherapy. Research Can Be Superb

Clinical Training

Heiberg, A.N 230

Short-Term Psychotherapy and Hypnosis

Frankl, F.H 236

Psychoanalysis and Brief Psychotherapy: Some New Considerations on

the Psychotherapeutic Process

Gilliéron, E 244

Short-Term Psychotherapy for the Borderline Personality Disorder

Leibovich, M.A 257

Short-Term Dynamic Psychotherapy: Progress, Problems, Perspectives

Pierloot, R 265

Book Review 271

Author Index 272

Contents Vol. 35 after 273

Acknowledgment

The editors want to express their gratitude to those who cooperated in making the II Hague Workshop on Short-Term Dynamic Psychotherapy a meaningful experience.

W. With special regards to the authors, Hoffmann-La Roche B.V., Mijdrecht, Ministry of Health and Environment, Leidschendam, Municipal Hospital Leyenburg, The Hague, and National Fund for Mental Health, Utrecht. 